\title{
STATUS PERNIKAHAN DAN DUKUNGAN SOSIAL SUAMI TERHADAP KUALITAS HIDUP WANITA MENOPAUSE DI KOTA PALANGKA RAYA
}

\author{
Itma Annah ${ }^{1}$, Harlyanti Muthma'innah Mashar ${ }^{2}$ \\ ${ }^{1,2}$ Poltekkes Kemenkes Palangka Raya \\ Email: itmaannah2605@gmail.com
}

\begin{abstract}
ABSTRAK
Menopause merupakan masa berhentinya siklus menstruasi secara permanen, menyebabkan menurunnya produksi hormone estrogen, progesterone dan testosterone. Beberapa gejala terjadinya menopause ialah Hot flashes, keringat pada malam hari, dan atrofi vagina yang mengakibatkan kekeringan pada vagina berhubungan dengan perubahan kadar hormon seks sehingga mengakibatkan penurunan kualitas hidup wanita menopause. Tujuan penelitian ini ialah melihat hubungan antara status pernikahan serta dukungan sosial suami terhadap kualitas hidup wanita menopause di Kota Palangka Raya. Instrumen yang digunakan untuk menilai kualitas hidup wanita menopause adalah menggunakan The Utian Quality of Life (UQOL) Scale. Metode penelitian yang digunakan ialah desain studi cross sectional. Hasil penelitian menunjukkan ada hubungan antara status pernikahan dengan kualitas hidup wanita menopause $(\mathrm{p}=0,000)$, begitu pula dukungan sosial suami $(\mathrm{p}=0,000)$. Oleh karena itu, sangat penting adanya dukungan keluarga khususnya suami dalam pemberian dukungan sosial bagi wanita menopause.
\end{abstract}

Kata kunci : Kualitas Hidup, Menopause, Status Pernikahan, Dukungan Suami 


\title{
MARRIAGE STATUS AND HUSBAND SOCIAL SUPPORT TO THE QUALITY OF LIVE MENOPAUSAL WOMEN AT PALANGKA RAYA CITY
}

\begin{abstract}
Menopause is a period of permanent cessation of the menstrual cycle, causing decreased production of the hormones estrogen, progesterone and testosterone. Some of the symptoms of menopause are hot flashes, night sweats, and vaginal atrophy resulting in vaginal dryness associated with changes in sex hormone levels resulting in decreased quality of life for menopausal women. The purpose of this study is to look at the relationship between marital status and husband's social support to the quality of life of menopausal women in Palangka Raya City. The instrument used to assess the quality of life of menopausal women is to use The Utian Quality of Life (UQOL) Scale. The research method used is a cross sectional study design. The results showed there was a relationship between marital status and the quality of life of menopausal women ( $p=$ $0,000)$, as well as husband's social support $(p=0,000)$. Therefore, it is very important that there is family support especially the husband in providing social support for menopausal women.
\end{abstract}

Keywords: Quality of Life, Menopause, Marriage Status, Husband Support 


\section{PENDAHULUAN}

Jumlah populasi wanita berumur 50 tahun atau lebih di dunia pada tahun 1990 mencapai angka 467 juta wanita dan akan bertambah menjadi 1,2 milyar pada tahun 2030 (Rozenbaum 1998). Hal ini menggambarkan adanya peningkatan pada angka harapan hidup khususnya wanita. Meningkatnya angka harapan hidup wanita juga berpengaruh pada meningkatnya jumlah wanita yang mengalami menopause pada sepertiga hidupnya (Mohamed, Lamadah, and Zamil 2014).

Data Profil Kesehatan Indonesia tahun 2017 menunjukkan bahwa hasil estimasi jumlah penduduk Indonesia pada tahun 2017 sebesar 261.890.872 jiwa, yang mana 130.311.688 jiwa diantaranya merupakan penduduk perempuan (Kemenkes RI 2017). Diperkiraakan ada $34,21 \%$ wanita yang memiliki umur rentan kejadian menopause yaitu umur 45 tahun ke atas (Kata Data Indonesia 2017). Di Kota Palangka Raya sendiri pada tahun 2017 ada $24,32 \%$ wanita yang berumur $\geq 45$ tahun yang merupakan umur rata-rata wanita mengalami menopause (Dinas Kesehatan Kota Palangka Raya 2018).

Menopause merupakan masa berhentinya siklus menstruasi secara permanen. Menopause bukanlah suatu penyakit melainkan transisi alamiah hidup seorang wanita yang dapat menyebabkan menurunnya produksi hormone estrogen, progesterone dan testosterone (International Menopause Society 2011). Gejala psikologis yang sering dikaitkan dengan menopause termasuk kelelahan, lekas marah, dan kecemasan. Beberapa gejala yang terkait dengan perubahan kadar hormon secara langsung terkait dengan penipisan estrogen. Hot flashes, keringat pada malam hari, dan atrofi vagina yang mengakibatkan kekeringan pada vagina berhubungan dengan perubahan kadar hormon seks (Ford et al. 2005).

Gejala-gejala lain, seperti gangguan tidur, kelelahan, kegelisahan, dan kenaikan berat badan umum terjadi pada wanita yang menopause, namun factor-faktor tersebut bersifat multi faktor dan terjadi juga pada wanita nonpascamenopause (Greenblum et al. 2013). Studi menemukan bahwa sebagian besar wanita mengalami setidaknya satu atau lebih dari gejalagejala ini ketika mereka berada pada fase transisi melalui tahap kehidupan pascamenopause (Lewis 2009).

Depresi dan gangguan kognitif dapat menjadi beban bagi wanita dan juga menambah beban penyakit medis bagi populasi wanita lanjut usia. Karena wanita pasca menopause sudah berisiko mengalami osteoporosis dan penyakit kardiovaskular, penting untuk mengatasi masalah kejiwaan yang berpotensi dapat terhadap masalah medis lebih lanjut. (Santoro, Epperson, and Mathews 2015). Salah satu cara mendeteksi secara dini permasalahan kejiwaan wanita yang menghadapi fase menopause yaitu dengan mengukur kualitas hidup wanita tersebut. Dan gejala-gejala tersebut dapat mempengaruhi kualitas hidup (Shobeiri et al. 2016).

Salah satu alat untuk menilai kualitas hidup wanita menopause adalah menggunakan The Utian Quality of Life 
(UQOL) Scale. Hasil pengukuran reliabilitas dan validitas substansial untuk skala dan subskalanya mendukung UQOL sebagai alat baru yang dapat digunakan dalam penelitian dan praktik klinis mengenai wanita menopause (WH et al. 2002).

Salah satu faktor yang mempengaruhi kualitas hidup wanita menopause adalah status pernikahan dan dukungan sosial suami. Studi dilakukan Chaerani dan Rahayu (2019) menekankan bahwa perempuan menopause memiliki kebutuhan untuk menyesuaikan diri terhadap perubahan tubuhnya dan perubahan peran sosialnya. Perlu adanya pemberian dukungan sosial, kepercayaan diri dan sikap positif terhadap keluhan yang dialami perempuan menopause sehingga dapat menerima menopause sebagai karunia karena bersifat normal bagi seorang perempuan (Astari, Tarawan, and Sekarwana 2014).

Melihat masalah yang telah dipaparkan diatas maka peneliti tertarik untuk melakukan penelitian mengenai hubungan antara status pernikahan dan dukungan sosial suami terhadap kualitas hidup wanita menopause Kota Palangka Raya.

\section{METODE PENELITIAN}

Jenis penelitian ini adalah penelitian kuantitatif yang bersifat observasional analitik dengan desain studi cross sectional dan uji chi-square. Penelitian dilakukan di wilayah kerja Puskesmas Kereng Bangkirai dan Puskesmas Menteng Kota Palangka Raya tahun 2019. Sampel dalam penelitian ini adalah wanita menopause yang berobat di Puskesmas Menteng dan Puskesmas Kereng Bangkirai dan memenuhi kriteria inklusi yakni sebanyak 66 orang. Pada penelitian ini, peneliti menggunakan sampel minimal size (untuk penentuan batas minimal dari besarnya sampel), sampel dapat ditentukan dengan rumus perhitungan besar sampel untuk Estimasi proporsi populasi (Lemeshow et al. 1997). Tehnik pengambilan sampel adalah dengan menggunakan metode accidental sampling. Sampel akan diambil dari pasien Puskesmas Menteng dan Puskesmas Kereng Bangkirai yang berkunjung selama waktu penelitian berlangsung. Pengumpulan data dilakukan teknik wawancara menggunakan kuesioner untuk menilai kualitas hidup, karakteristik responden, status pernikahan dan dukungan sosial suami. Pengolahan data dilakukan dengan menggunakan aplikasi SPSS 22.0 yang dianalisis uji chi square.

\section{HASIL DAN PEMBAHASAN Hasil}

Umur responden pada penelitian ini cukup bervariasi dengan range antara 42-79 tahun. Pada penelitian ini kelompok umur tertinggi ditemukan pada kelompok umur 61-70 tahun yaitu sebesar 26 orang, dengan presentase terbanyak $53,8 \%$ (14 orang) bertempat tinggal di daerah urban. Tingkat pendidikan tertinggi pada kelompok pasien yang mendapatkan pendidikan hanya sampai tingkat SD sebesar 21 orang dan $76,2 \%$ bertempat tinggal di daerah rural.Pada penelitian ini pekerjaan responden tertinggi ialah ibu 
rumah tangga yaitu sebanyak 32 orang, dan $84,4 \%$ diantaranya meninggal pada akhir pengamatan. Responden yang sudah menyandang status janda sebanyak 37 orang dan 51,4\% diantaranya bertempat tinggal di daerah rur

Tabel 1. Distribusi Wanita Menopause berdasarkan

Karakteristik Responden di Puskesmas Menteng dan Puskesmas Kereng Bangkirai Kota Palangka Raya tahun 2019

\begin{tabular}{ccc}
\hline Karakteristik Responden & \multicolumn{2}{c}{ Jumlah } \\
\cline { 2 - 3 } & n & \% \\
\hline Kelompok Umur & 10 & 15,15 \\
$41-50$ & 22 & 33,33 \\
$51-60$ & 26 & 39,39 \\
$61-70$ & 8 & 12,12 \\
$71-80$ & & \\
Tingkat Pendidikan & 3 & 4,54 \\
Tidak Sekolah & 6 & 9,09 \\
Tidak Tamat SD & 21 & 31,8 \\
Tamat SD & 12 & 18,18 \\
Tamat SMP & 16 & 24,24 \\
Tamat SMA & 8 & 12,21 \\
Perguruan Tinggi & & \\
Pekerjaan & 46 & 69,69 \\
IRT & 9 & 13,63 \\
Wiraswasta & 3 & 4,54 \\
PNS / TNI / POLRI & 4 & 6,06 \\
Petani & 4 & 6,06 \\
Lain-lain & & \\
Status Pernikahan & 1 & 1,51 \\
Belum Kawin & 28 & 42,42 \\
Kawin & 37 & 56,06 \\
Janda & 66 & 100,0 \\
Jumlah & &
\end{tabular}

Sumber : Data Primer

Tabel 2 menunjukkan hasil analisis hubungan antara kualitas hidup wanita menopause dengan variabel status pernikahan dan dukungan sosial suami. Hasil analisis menunjukkan bahwa wanita menopause yang berstatus janda memiliki kualitas hidup kurang yang paling tinggi yaitu 26 orang $(70,3 \%)$ sedangkan wanita menopause dengan kualitas hidup baik tertinggi ialah wanita menopause dengan status kawin sebanyak 23 orang $(82,1 \%)$. Nilai $\mathrm{p}=0,000<0,05$ yang berarti ada hubungan antara kualitas hidup wanita menopause dan status pernikahan dan terbukti secara statistik.

Hasil analisis menunjukkan bahwa wanita menopause dengan dukungan 
suami rendah memiliki kualitas hidup kurang yang paling tinggi yaitu 28 orang $(70,3 \%)$ sedangkan wanita menopause dengan kualitas hidup baik tertinggi ialah wanita menopause dengan dukungan suami tinggi yaitu 23 orang $(82,1 \%)$. Nilai $\mathrm{p}=0,000<0,05$ yang berarti ada hubungan antara kualitas hidup wanita menopause dan status pernikahan dan terbukti secara statistik.

Tabel 2. Hubungan Kualitas Hidup Wanita Menopause dengan Variabel Independen

\begin{tabular}{cccccccc}
\hline $\begin{array}{c}\text { Variabel } \\
\text { Independen }\end{array}$ & $\begin{array}{c}\text { Kualitas } \\
\text { Hidup } \\
\text { Kurang }\end{array}$ & \multicolumn{2}{c}{$\begin{array}{c}\text { Kualitas } \\
\text { Hidup } \\
\text { Baik }\end{array}$} & Jumlah & \multirow{2}{*}{ p } \\
\cline { 2 - 6 } & $\mathbf{n}$ & $\mathbf{\%}$ & $\mathbf{n}$ & $\mathbf{\%}$ & $\mathbf{n}$ & $\mathbf{\%}$ & \\
\cline { 1 - 5 } Status Pernikahan & & & & & & \\
Belum Kawin & 0 & 0,0 & 1 & 100,0 & 1 & 100.0 & \\
$\quad$ Kawin & 5 & 17,9 & 23 & 82,1 & 28 & 100.0 & \multirow{2}{*}{0,000} \\
Janda & 26 & 70,3 & 11 & 29,7 & 37 & 100.0 & \\
Dukungan Sosial Suami & & & & & & \\
Rendah & 26 & 70,3 & 11 & 9,7 & 37 & 100.0 & \\
Sedang & 0 & 0,0 & 1 & 100,0 & 1 & 100.0 & \multirow{2}{*}{0,000} \\
$\quad$ Tinggi & 5 & 17,9 & 23 & 82,1 & 28 & 100.0 & \\
Jumlah & 31 & 47,0 & 35 & 53,0 & 66 & 100.0 & \\
\hline
\end{tabular}

Sumber : Data Primer

\section{Pembahasan}

Pada penelitian ini, terdapat 31 orang atau $41,7 \%$ dari 66 wanita menopause yang memiliki kualitas hidup kurang berdasarkan instrument UQOL. Instrumen UQOL adalah persepsi atau pandangan subjektif wanita menopause terhdap kesempatan untuk dapat hidup nyaman, mempertahankan keadaan fisiologis sejalan dengan imbangan psikologis di dalam kehidupan sehari-hari. Tingkat kualitas hidup dinilai dengan menentukan nilai tengah dari nilai skor terendah dan nilai skor tertinggi dari kuesioner, disini didapatkan nilai terendah 23 dan nilai tertinggi 115 , jadi didapatkan nilai tengah 69. Dari pengumpukan data yang dilakukan kepada 66 wanita menopause didapatkan rata-rata score UQOL adalah 70,08; dengan nilai minimum 42 dan nilai maksimal yaitu 115 .

Tingginya angka kualitas hidup yang rendah pada wanita menopause disebabkan ketika masa menstruasi seorang wanita berakhir maka ovarium berhenti memproduksi estrogen dan progesteron. Penurunan kadar hormon-hormon tersebut menyebabkan wanita mengalami gejala menopause yang dapat menurunkan kualitas hidup mereka. Menopause menyebabkan lebih dari $80 \%$ wanita mengalami keluhan fisik dan psikologis dengan berbagai tekanan dan gangguan penurunan kualitas hidup (Esposito et al. 2007) 


\section{Status Pernikahan}

Hasil analisis penelitian ini menunjukkan ada hubungan kualitas hidup wanita menopause dengan status pernikahan. Hal ini dibuktikan dengan angka hasil penelitian wanita menopause yang berstatus janda memiliki kualitas hidup kurang yang paling tinggi yaitu 26 orang (70,3\%) sedangkan wanita menopause dengan kualitas hidup baik tertinggi ialah wanita menopause dengan status kawin sebanyak 23 orang $(82,1 \%)$. Nilai $\mathrm{p}=0,000<0,05$ yang berarti ada hubungan antara kualitas hidup wanita menopause dan status pernikahan dan terbukti secara statistik.

Hal ini sejalan dengan hasil penelitian yang dilaksanakan di Thailand yang menyatakan bahwa status pernikahan merupakan faktor independen terhadap kualitas hidup wanita menopause dengan nilai $\mathrm{p}=0,003$ (Panichkul et al. 2016). Begitu pula halnya dengan penelitian di Nepal yang menyatakan Wanita lajang / janda atau bercerai memiliki kualitas hidup yang buruk dibandingkan dengan wanita yang hidup dengan suami mereka ( $\mathrm{p}=$ 0,026) (Koirala and Manandhar 2018).

Responden yang belum menikah/janda menyatakan lebih sering rasa sakitnya menghambat aktivitas mereka dan kurang puas terhadap kualitas tidur mereka. Mereka yang menikah memiliki nilai rata-rata domain sosial yang lebih tinggi daripada yang belum menikah/janda. Mengenai dukungan yang dari diperoleh dari orang-orang disekitar mereka dan kehidupan seksual, responden yang belum menikah/janda lebih banyak menyatakan kurang puas terhadap halhal tersebut. Hal tersebut dapat dikarenakan mereka tidak memiliki pasangan hidup yang biasanya diajak berkomunikasi dan tempat berbagi cerita (Putri, Wati, and Ariyanto 2014).

Dukungan keluarga adalah sikap, tindakan, dan penerimaan keluarga terhadap penderita yang sakit. Anggota keluarga memandang bahwa orang yang bersifat mendukung selalu siap memberikan pertolongan dan bantuan jika diperlukan. Dukungan keluarga khsuusnya suami diartikan sebagai bantuan yang diberikan oleh anggota keluarga yang lain sehingga akan memberikan kenyamanan fisik dan psikologis pada orang yang diharapkan pada situasi stres.

\section{Dukungan suami}

Dukungan suami merupakan salah satu faktor yang dapat mempengaruhi kualitas hidup wanitapada masa menopause. Suami memiliki peran yang besar dalam menjalani kehidupan menopause,dimana suami yang dapat menerima kondisi perubahan saat menopause dapat membuat wanita tidak khawatir terhadap perubahan fisik yang terjadi (Noorma 2017).

Pada hasil penelitian ini menunjukkan bahwa wanita menopause dengan dukungan suami rendah memiliki kualitas hisup kurang yang paling tinggi yaitu 28 orang $(70,3 \%)$ sedangkan wanita menopause dengan kualitas hidup baik tertinggi ialah wanita menopause dengan dukungan suami tinggi yaitu 23 orang $(82,1 \%)$. 
Nilai $\mathrm{p}=0,000<0,05$ yang berarti ada hubungan antara kualitas hidup wanita menopause dan status pernikahan dan terbukti secara statistik.

Hasil penelitian ini sejalan dengan peneitian yang dilakukan oleh Wardani pada tahun 2019. Hasil penelitian yang dilakukan kepada 126 responden mendapatkan nilai $\mathrm{p}$ sebesar 0,032 yang membuktikan bahwa ada hubungan antara dukungan suami dan kualitas hidup wanita menopause. Perubahan psikologis dan fisik pada wanita menopause akan memengaruhi kualitas hidup mereka. Oleh karena itu, dukungan dari orang-orang terdekat, terutama dari suami mereka diperlukan. Harus ada penelitian lanjutan tentang faktor-faktor yang mempengaruhi kualitas hidup wanita menopause seperti aspek psikologis, fisik, hubungan sosial dan lingkungan sekitar wanita menopause (Wardani 2019).

\section{SIMPULAN}

Kesimpulan dari penelitian ini adalah Berdasarkan hasil penelitian dan analisis data yang dilakukan maka dapat ditarik kesimpulan bahwa ada hubungan antara status pernikahan dan dukungan sosial suami terhadap kualitas hidup wanita menopause Kota Palangka Raya dengan $\mathrm{p}$ value masing-masing sebesar 0,000 .

Untuk penelitian lebih lanjut disarankan untuk melakukan penelitian mengenai faktor-faktor yang mempengaruhi kualitas hidup wanita menopause seperti aspek psikologis, fisik, hubungan sosial dan lingkungan sekitar wanita menopause. Serta perlunya suatu kebijakan atau program mengenai peningkatan pengetahuan keluarga khususnya suami terhadap pemberian dukungan sosial terhadap wanita menopause.

\section{UCAPAN TERIMA KASIH}

Pada kesempatan ini, peneliti ingin mengucapkan terima kasih kepada berbagai pihak yang telah membantu terwujudnya penelitian ini :

1. Kepala Puskesmas Menteng Kota Palangka Raya

2. Kepala Puskesmas Kereng Bangkirai Kota Palangka Raya

\section{DAFTAR PUSTAKA}

Astari, Ruri Yuni, Vita Murniati Tarawan, and Nanan Sekarwana. 2014. "Correlation between Menopausal Syndrome and Quality of Life Menopause Women in Sukahaji District Majalengka." Buletin Penelitian Kesehatan 42(3): 171-84.

Chaerani, Rachma Fajri, and Anizar Rahayu. 2019. "Penerimaan Diri Dan Dukungan Sosial Hubungannya Dengan Penyesuaian Diri Wanita Yang Menghadapi Masa Menopause." Ikraith-Humaniora 3(2): 133-37.

Dinas Kesehatan Kota Palangka Raya. 2018. Profil Kesehatan Kota Palangka Raya Tahun 2017.

Esposito, K. et al. 2007. "Association of Body Weight with Sexual Function in Women." Int J Impot Res 19(4).

Ford, Kathleen et al. 2005. "A Longitudinal Study of the Predictors of Prevalence and Severity of Symptoms Commonly Associated with Menopause." Menopause 12(3): 308-17. 
Greenblum, Catherine A., Meredeth A. Rowe, Donna Felber Neff, and Jesse S. Greenblum. 2013. "Midlife Women: Symptoms Associated with Menopausal Transition and Early Postmenopause and Quality of Life." Menopause 20(1): 22-27.

International Menopause Society. 2011. Women and Menopause Factsheet. www.imsociety.prg.

Kata Data Indonesia. 2017. "Piramida Penduduk Indonesia Tahun 2017.”

Kemenkes RI. 2017. Profil Kesehatan Indonesia Tahun 2017.

Koirala, Sunita, and Naresh Manandhar. 2018. "Quality of Life of Peri and Postmenopausal Women Attending Outpatient Department of Obstretics and Gynecology of A Tertiary Care Hospital." 16(1): 32-35.

Lemeshow, S, DW Hosmer, J Klar, and SK Lwanga. 1997. Adequacy of Sample Size in Health Studies. Yogyakarta: Gadjah Mada University Press.

Lewis, Vivian. 2009. "Undertreatment of Menopausal Symptoms and Novel Options for Comprehensive Management." Current Medical Research and Opinion 25(11): 268998.

Mohamed, Hoda A.E., Sahar M. Lamadah, and Luma Gh. Al. Zamil. 2014. "Quality of Life among of Menopausal Women." International Journal of Reproduction, Contraception, Obstetrics and Gynecology 3(3): 552-61. www.ijrcog.org.

Noorma, Nilam. 2017. "WANITA MENOPAUSE DI KLINIK BANK TABUNGAN." Jurnal Husada
Mahakam IV(4): 240-54.

Panichkul, Suthee et al. 2016. "MenopauseRelated Symptoms and Quality of Life in Peri- and Postmenopausal Women in Thailand: A Multicenter Study." Asian Biomedicine 11(3): 207-16.

Putri, Dessy Irwienna, Dwi Martiana Wati, and Yunus Ariyanto. 2014. "Kualitas Hidup Wanita Menopause." Pustaka Kesehatan 2(1): 167-74.

Rozenbaum, H. 1998. "Why Has Menopause Become a Public Health Problem?" Therapie 53(1): 49-59.

Santoro, Nanette, C. Neill Epperson, and Sarah B. Mathews. 2015. "Menopausal Symptoms and Their Management." Endocrinol Metabolism Clinics of North America 44(3): 497-2515.

Shobeiri, Fatemeh, Ensiyeh Jenabi, Seyyed Mohammad Mahdi Hazavehei, and Ghodratollah Roshanaei. 2016. "Quality of Life in Postmenopausal Women in Iran: A Population-Based Study." Journal of menopausal medicine 22(1): 31-38. http://www.pubmedcentral.nih.gov/art iclerender.fcgi?artid=4854657\&tool= pmcentrez\&rendertype $=$ abstract.

Wardani, Desy. 2019. "Hubungan Dukungan Suami Dengan Kualitas Hidup Perempuan Menopause." Jurnal Medika: Karya Ilmiah Kesehatan 4.

WH, Utian et al. 2002. "The Utian Quality of Life (UQOL) Scale: Development and Validation of an Instrument to Quantify Quality of Life through and beyond Menopause." Menopause 9(6): 402-10. 